\title{
LES FLUX D'ÉTUDIANTS SUSCEPTIBLES D'ACCÉDER AUX CARRIÈRES DE RECHERCHE
}

\section{L'exemple de l'Ile-de-France dans le cadre national}

Rapport coordonné par Jean Dercourt Secrétaire perpétuel de l'Académie des sciences

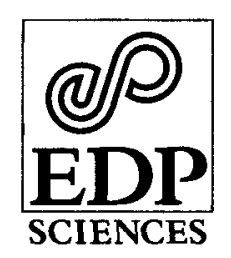

17, avenue du Hoggar

Parc d'Activité de Courtabœuf, BP 112 91944 Les Ulis Cedex A, France 
ISBN : 2-86883- 751-4

Tous droits de traduction, d'adaptation et de reproduction par tous procédés, réservés pour tous pays. La loi du 11 mars 1957 n'autorisant, aux termes des alinéas 2 et 3 de l'article 41 , d'une part, que les « copies ou reproductions strictement réservées à l'usage privé du copiste et non destinées à une utilisation collective », et d'autre part, que les analyses et les courtes citations dans un but d'exemple et d'illustration, « toute représentation intégrale, ou partielle, faite sans le consentement de "'auteur ou de ses ayants droit ou ayants cause est illicite " (alinéa $1^{\text {er }}$ de l'article 40 ). Cette représentation ou reproduction, par quelque procédé que ce soit, constituerait donc une contrefaçon sanctionnée par les articles 425 et suivants du code pénal.

(C) Académie des sciences 2004

(C) EDP Sciences 2004 